\title{
Cartilage intermediate layer protein affects the progression of intervertebral disc degeneration by regulating the extracellular microenvironment (Review)
}

\author{
LIBANGXI LIU ${ }^{1}$, JINYUE HE ${ }^{2}$, CHANG LIU ${ }^{1}$, MINGHUI YANG ${ }^{1}$, JIAWEI FU ${ }^{1}$, \\ JIARONG YI $^{1}$, XUEZHENG AI ${ }^{1}$, MIAO LIU ${ }^{3}$, YONG ZHUANG ${ }^{3}$, YAQING ZHANG ${ }^{1}$, \\ BO HUANG ${ }^{1}$, CHANGQING LI ${ }^{1}$, YUE ZHOU ${ }^{1}$ and CHENCHENG FENG ${ }^{1}$ \\ ${ }^{1}$ Department of Orthopedics, Xinqiao Hospital, Army Medical University; ${ }^{2}$ Department of Orthopedics,
Xi'nan Hospital, Army Medical University, Chongqing 400037; ${ }^{3}$ Department of Orthopedics,
Affiliated Hospital of Guizhou Medical University, Guiyang, Guizhou 550004, P.R. China
}

Received July 18,2020; Accepted November 27, 2020

DOI: $10.3892 / \mathrm{ijmm} .2020 .4832$

\begin{abstract}
Intervertebral disc degeneration (IDD), which is caused by multiple factors, affects the health of individuals and contributes to low back pain. The pathology of IDD is complicated, and changes in the extracellular microenvironment play an important role in promoting the process of degeneration. Cartilage intermediate layer protein (CILP) is a matrix protein that resides in the middle of human articular cartilage and is involved in numerous diseases that affect cartilage. However, there is no detailed review of the relationship between CILP and degenerative disc disease. Growing evidence has revealed the presence of CILP in the extracellular microenvironment of intervertebral discs (IVDs) and has suggested that there is a gradual increase in CILP in degenerative discs. Specifically, CILP plays an important role in regulating the metabolism of the extracellular matrix (ECM), an important component of the extracellular microenvironment. CILP can combine with transforming growth factor- $\beta$ or insulin-like growth factor-1 to regulate the ECM synthesis of IVDs and influence the balance of ECM metabolism, which leads to changes in the extracellular microenvironment to promote the process of IDD. It may be possible to show the correlation of CILP with IDD and to target CILP to interfere with IDD. For this purpose, in the present study, the current knowledge on CILP was summarized and a detailed description of CILP in discs was provided.
\end{abstract}

Correspondence to: Professor Yue Zhou or Dr Chencheng Feng, Department of Orthopedics, Xinqiao Hospital, Army Medical University, 183 Xinqiao Main Street, Chongqing 400037, P.R. China E-mail: happyzhou@vip.163.com

E-mail: doctorfgy@163.com

Key words: intervertebral disc degeneration, cartilage intermediate layer protein, extracellular microenvironment, transforming growth factor- $\beta$, insulin-like growth factor- 1

\section{Contents}

1. Introduction

2. Intervertebral disc degeneration (IDD) pathogenesis

3. Structure and synthesis of CILP

4. Association between cartilage intermediate layer protein (CILP) and IDD

5. Function of CILP in IDD

6. Regulation of CILP

7. Conclusions and future directions

\section{Introduction}

Low back pain (LBP) is one of the most prevalent musculoskeletal diseases worldwide. Approximately $70-85 \%$ of adults suffer from LBP in their lifetime, and a great number of them are disabled by it (1). The cost for treatment can reach billions of dollars, creating a huge burden for the families of patients and society (2). However, as a result of the complex pathology of LBP and the poor performance of current therapeutic measures, LBP still constitutes a major threat to the health of people.

There are numerous pathogenic factors leading to LBP, with intervertebral disc degeneration (IDD) being the most common target for diagnosis and intervention (3-5). As the largest avascular and aneural tissue in the human body, the normal intervertebral discs (IVDs) are made up of three morphologically distinct regions, the nucleus pulposus (NP), annulus fibrosus (AF) and cartilaginous endplates (CEPs) (6-9). IVDs function through dampening excessive mechanical stresses and maintaining the stability of the spine (10). It is important to provide thorough insight into the complicated pathophysiological process of IDD, in order to develop a strategy for the prevention and treatment of LBP. IDD is a multifactorial result characterized by an aberrant cell-mediated response that gradually causes structural failure (11). Aberrant cell-mediated responses to the changed microenvironment include an imbalanced extracellular matrix (ECM) metabolism, an upregulated 
proinflammatory phenotype and senescence (12-15). During this process, the upregulation of proinflammatory and procatabolic phenotypes by NP cells is the main contributor to the suppression of anabolism and promotes the catabolism of the $\operatorname{ECM}(16,17)$.

Cartilage intermediate layer protein (CILP) is a monomeric glycoprotein residing in the ECM that is mainly expressed in the intermediate zone between human IVDs and articular cartilage (18-20). Previous studies have also revealed the existence of a tendon ligament (21) and a synovial membrane (22). Notably, CILP expression in disc tissues has been revealed to be increased as degeneration and aging progress, contrary to the decreased levels of collagen II and aggrecans, which are the main components of discs (23). Furthermore, recent studies have revealed that CILP-overexpression in human NP cells can negatively regulate matrix synthesis (24). In the aberrantly expressed genes detected in IDD, CILP is among the few cartilage matrix proteins whose expression is upregulated in the early and late stages of cartilage diseases $(19,25)$, and a genetic association has been revealed between the CILP gene and IDD, suggesting the importance of CILP beyond that of other structural genes (26). The relationship between CILP and IDD has received increasing attention in recent years. Herein, insight was first provided concerning the pathogenesis of IDD, and the genetic and molecular structure of CILP was described. Next, a detailed introduction of the function of CILP in IVDs was provided, and the genetic structure of the association between CILP and cartilage diseases was described. The regulatory mechanism of CILP was then summarized. Finally, the discussion focused on the future perspectives of CILP in biological therapies for IDD.

\section{Intervertebral disc degeneration (IDD) pathogenesis}

IDD is a multifactorial result caused by aging, infection, smoking, mechanical overloading, nutrient deficiency and genetic predisposition (27-31). Among the numerous factors that lead to IDD, the destruction of extracellular microenvironmental homeostasis is considered to be one of the most important factors. All the etiologic causes initiate the process of IDD, which is mediated and characterized by an enhanced proinflammatory phenotype (32-34). The increased inflammatory chemokine level, secreted from disc cells, infiltrates immune and AF cells, greatly destroying the homeostasis of the microenvironment around disc cells and directly affecting the metabolism of NP cells, which leads to a disruption of the balance between the anabolism and degradation of the ECM that directly accelerate the degradation of the ECM (35-38). As a result, the resident cells are exposed to excessive mechanical stress, which in turn further worsens the ECM metabolism of NP cells (24). In addition, the nociceptive nerve fibers and blood vessels from the dorsal root ganglion intrude into the herniated disc tissues to cause LBP (Fig. 1) $(39,40)$. Notably, gene susceptibility has also been revealed to be involved in the initiation and progression of IDD; CILP is among the susceptible genes that are aberrantly expressed in IVDs $(41,42)$. Moreover, CILP is restrictively expressed in few cartilage tissues, including articular cartilage and disc tissues $(18,26)$, which suggests the importance of CILP beyond other susceptibility genes, elucidates the function of CILP and contributes to a better understanding of the pathogenesis of IDD.

\section{Structure and synthesis of CILP}

CILP was first identified and isolated by Lorenzo et al in 1998; this protein was named for its deposition in the interterritorial matrix without a presence in the superficial or deepest regions of the articular cartilage (18). CILP is synthesized by cartilage chondrocytes and is a polypeptide of 1,184 amino acids with a molecular mass of $132.5 \mathrm{kDa}$. Apart from a putative signal peptide of 21 amino acids, the protein is comprised of 2 distinct polypeptides (20). The $\mathrm{N}$-terminus corresponds to the classical CILP protein, while the C-terminus corresponds to a homologue of porcine nucleotide pyrophosphatase phosphodiesterase (NPP) (Fig. 2C and D). The CILP gene, which evolved from independent ancestral genes spanning $15.3 \mathrm{Kbp}$ of genomic DNA, resides on chromosome 15q22 $(43,44)$. Human CILP cDNA consists of 9 exons and 8 introns, of which exons 3-6 are symmetrical, while exons 7 and 8 are asymmetrical (Fig. 2A). There is a putative promoter region upstream of the encoding start site at the 5 ' flanking region, where regulatory elements such as GATA-1, MyoD, MZF1 and CdxA have been detected (Fig. 2B) (44). Exon 1 covers 46 bp of the noncoding region, and the eukaryotic translation of the $\mathrm{N}$-terminal region corresponding to the CILP protein begins at exon $2(43,45)$. Of the exons that are translated, exons 2 to 8 are 46-154 bp long, and only exon 9 exceeds 2,800 bp (44). Furthermore, exon 9 not only participates in the protein translation of CILP but also encodes the C-terminal protein, a homologue to porcine nucleotide pyrophosphohydrolase, which has piqued the interest of researchers due to its possible involvement in calcium pyrophosphate dihydrate (CPPD) deposition disease $(44,46)$.

By means of transcriptome profiling, a homologue to CILP1 (the classical CILP) was discovered in mouse cartilage (47). During the stage before maturation, CILP2 mainly focuses on the surface of the cartilage. As maturation progresses, the homologue gradually collocates in the intermediate zone with CILP1 (47). However, there are also differences between the two analogs. In surgery-induced osteoarthritis, CILP2 was significantly downregulated, while CILP1 was upregulated. Ultrastructure analysis suggested that CILP2 may be relevant to collagen VI, which is a normal component in cartilage tissues, and that CILP2 may play a role in cartilage by mediating the interaction among the matrix components; more studies are required to test this hypothesis (47).

\section{Association between cartilage intermediate layer protein (CILP) and IDD}

In a 2005 study, Seki et al first revealed that the CILP is a key regulatory factor in IDD development (19). At the mammalian model level, Seki et al used transgenic mice that overexpressed CILP, and although there was no significant change in the X-ray analysis results, blood-test values or body weight, MRI analysis detected an obviously lower intensity in the area where CILP was deposited (25). In addition, through the detection and analysis of CILP content in IVDs of rabbits of different ages, it was revealed that the expression 


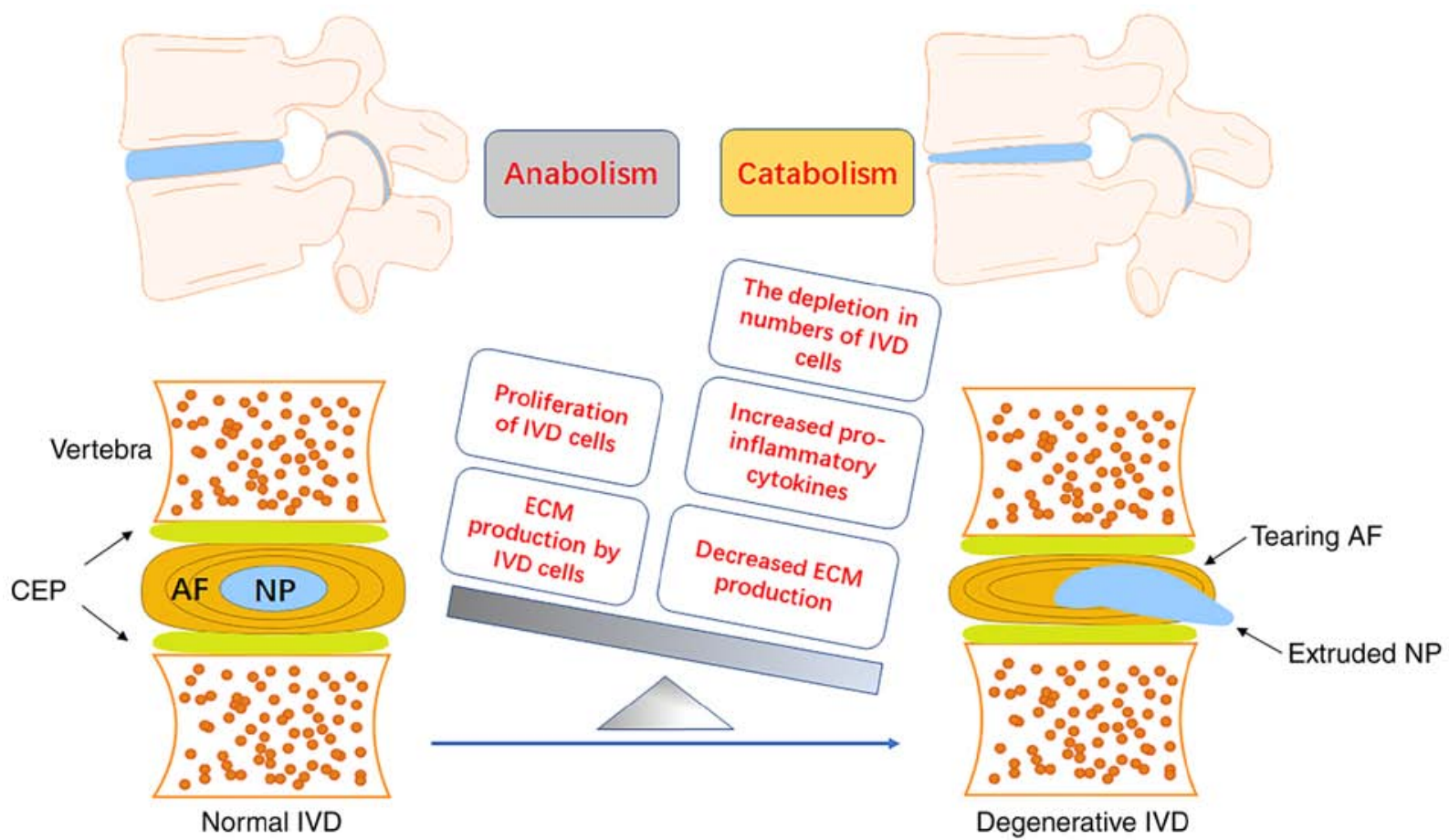

Figure 1. Development of IVD degeneration. A normal IVD is a typical sandwich structure that consists of 2 CEP, 1 AF and 1 NP. The interaction of environmental and genetic factors may lead to the degeneration of IVDs. The imbalance of anabolism and catabolism in IVD cells leads to the metabolic disturbance of the IVD microenvironment and accelerates the process of IDD. The aging or apoptosis of IVD cells reduces the production of ECM, increases the production of pro-inflammatory cytokines and ECM degradation enzymes, and promotes the catabolism of IVD cells. IVDs, intervertebral disc; CEP, cartilage endplates; AF, anulus fibrosus; NP, nucleus pulposus; IDD, intervertebral disc degeneration; ECM, extracellular matrix.

A $5^{\prime}$

$3^{\prime}$

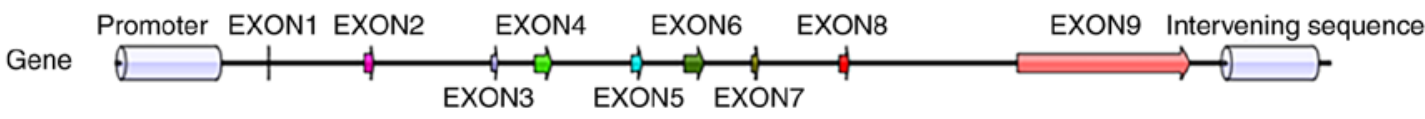

B

Promoter

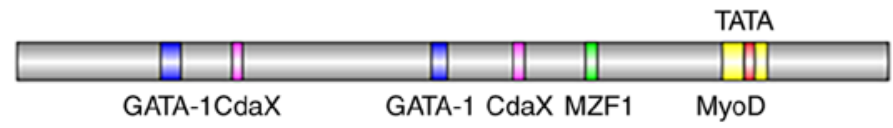

GATA-1: $-343 /-332$ bp, $-198 /-189$ bp

CdaX: $-306 /-300$ bp, $-254 /-248$ bp

MZF1: $-116 /-108$ bp, MyoD: $-41 /-30$ bp TATA: $-29 /-23$ bp

C

\begin{tabular}{|l|c|} 
CILP precursor protein & CILP \\
\cline { 2 - 3 }
\end{tabular}

Signal peptide

D

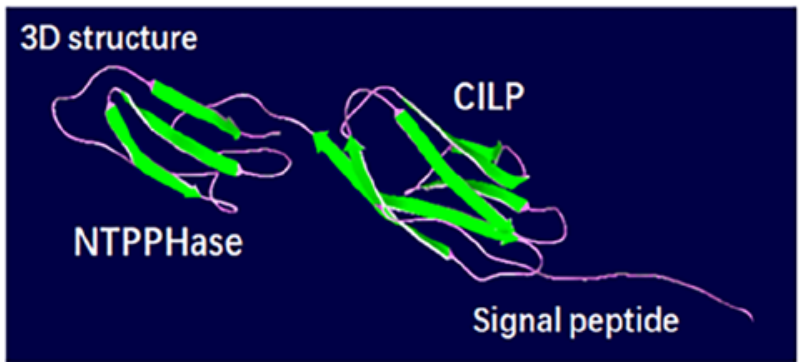

Figure 2. Genetic and protein structure of CILP in humans. (A) Genetic structure of CILP in humans. (B) Approximately 450 bp of human CILP promoter and its major regulatory binding elements, as well as factors that signal through these sites and their downstream effector factors. (C) Planar structure of a human CILP protein. (D) 3D structure of a human CILP protein. CILP, cartilage intermediate layer protein; NTPPHase, porcine 127-kDa nucleotide pyrophosphohydrolase. 


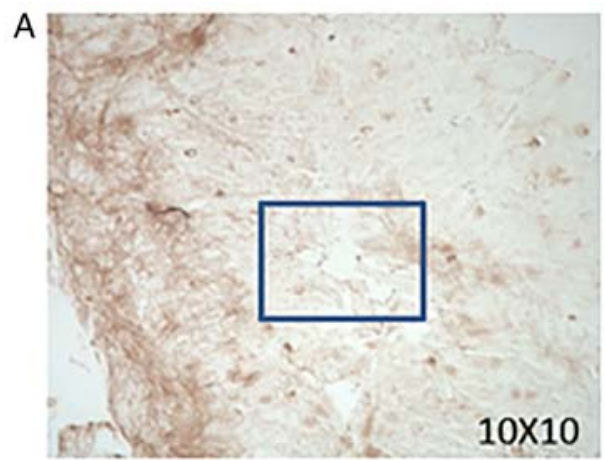

B
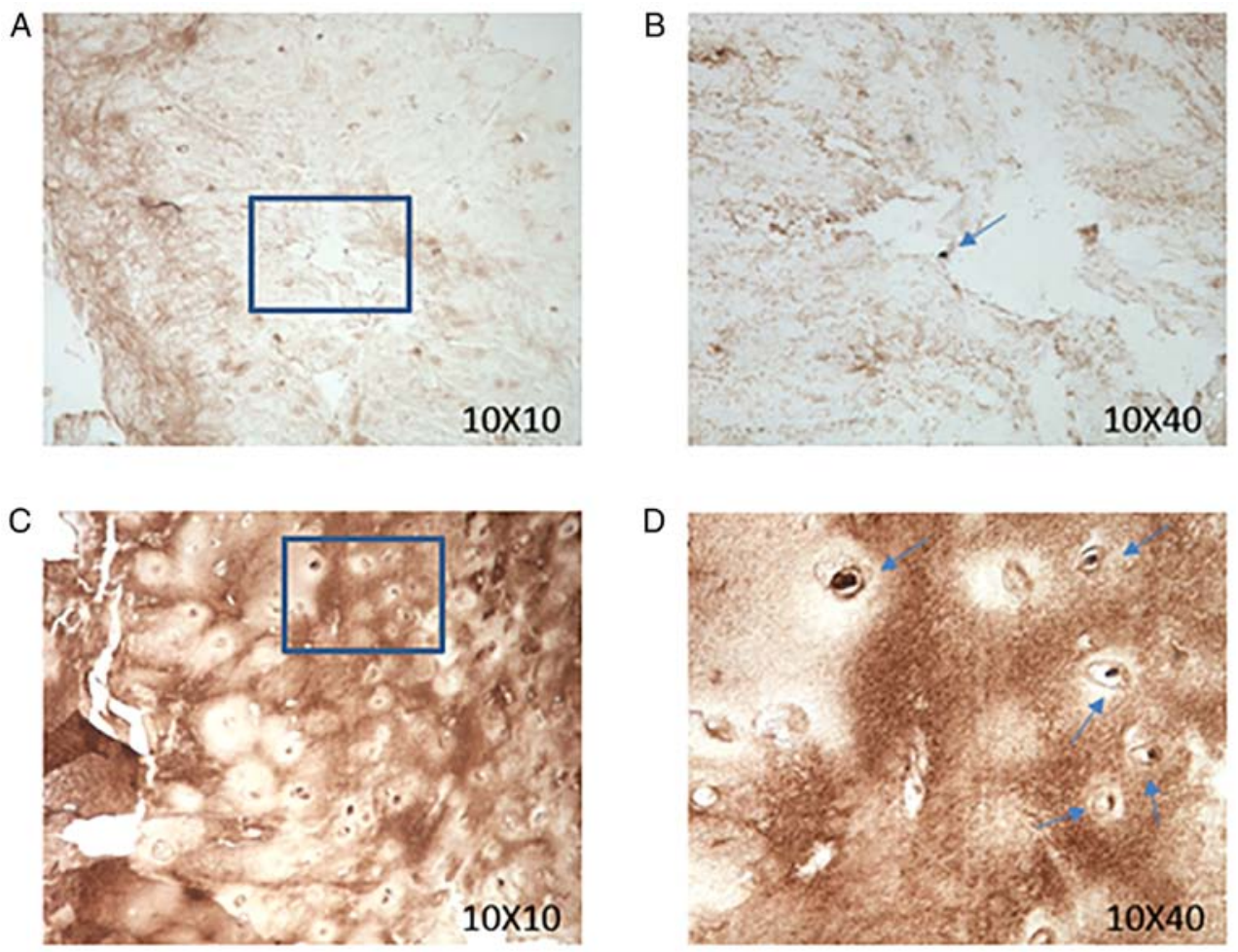

Figure 3. Expression of CILP in human intervertebral disc tissue increases with the degree of degeneration. (A and B) CILP immunohistochemical staining of Pfirrmann grade I (low degree of degeneration of intervertebral disc tissue). (C and D) CILP immunohistochemical staining of Pfirrmann grade III (high degree of degeneration of intervertebral disc tissue). Blue arrow, CILP expression positive; 10x10, zoom in 100 times; 10x40, zoom in 400 times. CILP, cartilage intermediate layer protein; NTPPHase, porcine 127-kDa nucleotide pyrophosphohydrolase.

level of CILP in IVDs in aged rabbits was significantly increased (23). Previous research has not reported CILP expression levels in human IVDs. Therefore, we collected human IVDs with varying degrees of degeneration and assessed their CILP expression levels. Human IVD tissues were collected from 18 patients (male:female, 1:1) ranging in age from 20-65 years who were undergoing lumbar spinal surgery for IDD between October 2019 and May 2020, at the Department of Orthopedics of The Second Affiliated Hospital (Chongqing, China). The present study was approved by the Ethics Committee of Xinqiao Hospital (Chongqing, China) on October 1, 2019 at the implementation of the study. All subjects provided their informed consent before participating in the present study. Immunohistochemical staining of a CILP antibody was performed in human disc paraffin sections with different degrees of degeneration in Pfirrmann grades. In brief, the tissues were fixed in $4 \%$ paraformaldehyde at $25^{\circ} \mathrm{C}$ for $48 \mathrm{~h}$. Dehydrated tissue was immersed in xylene for $2 \mathrm{~h}$ for transparent treatment and then immersed in section paraffin for $2.5 \mathrm{~h}$. The tissue sections were $5-\mu \mathrm{m}$ thick. Then, the sections were blocked in normal goat serum (cat. no. SL038; Solarbio Life Sciences) that was diluted 20 times with PBS and added directly to the slices for $10-30 \mathrm{~min}$ at $37^{\circ} \mathrm{C}$. Tissue sections were then incubated with CILP Polyclonal Antibody (rabbit/IgG; dilution, 1:200; cat. no. PA5-51856; Thermo Fisher Scientific, Inc.) at $4^{\circ} \mathrm{C}$ for $12 \mathrm{~h}$. Following primary incubation, the sections were incubated with HRP-conjugated goat anti-rabbit IgG (dilution, 1:100; cat. no. SA134; Solarbio Life Sciences) at room temperature $\left(25^{\circ} \mathrm{C}\right)$ for $1 \mathrm{~h}$. The sections were observed using a light microscope (magnifications, $10 \times 10$ and 10 X 40). The expression of CILP was revealed to be increased in human disc paraffin sections with higher degrees of degeneration (Fig. 3). Quantitative proteomic analysis of the IVDs of different IDD level groups revealed that CILP expression was significantly increased in the IVDs of people with severe IDD, specifically, in NP tissue, there was more CILP expression in the degenerate sample (26). In recent years, genetic susceptibility analysis of diseases to obtain the degree of genetic correlation with diseases has been widely used. A study consisting of 467 Japanese patients and 654 controls revealed that the single nucleus polymorphism (SNP) rs2073711 at the 1,184 allele (T to C) was genetically correlated with IDD (19). Furthermore, the substitution from $\mathrm{T}$ to $\mathrm{C}$ increased the binding of CILP to transforming growth factor- $\beta$ (TGF- $\beta$ ), which enhanced the CILP-mediated suppression of the pro-anabolic effect mediated by TGF- $\beta$; this substitution plays an important role in the pathogenesis and origin of IDD (19). A meta-analysis of genetic association studies of IVDs using a total of 1,551 IVD cases and 1,793 controls from the 5 studies which were used in this study, and comprising four Asian populations and two European populations, confirmed the positive association between the CILP gene and IVDs (48). However, the correlation was absent in a Chinese sample with 691 cases, a Finnish sample with 502 cases and an Indian sample with 342 cases $(49,50)$. It appears that the genetic predisposition of CILP for IDD varies with population differences, which can explain the discrepancy among different ethnicities. Moreover, two studies further complicated the differential predisposition of CILP, as they revealed the genetic association between 


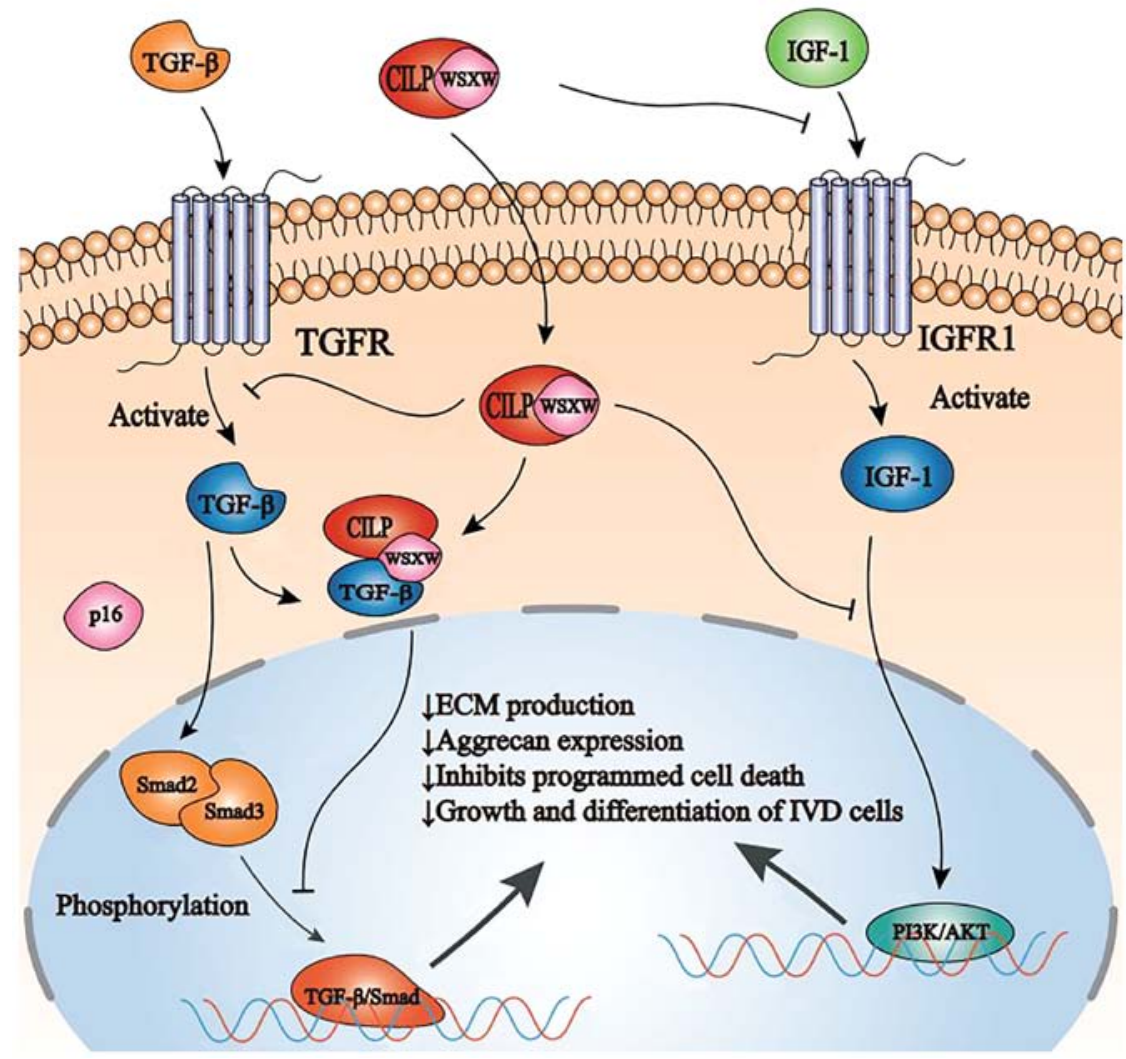

Figure 4. Schematic representation of CILP function and regulation in NP cells by TGF- $\beta$ and IGF-1. CILP inhibits SMAD2/3 phosphorylation, either directly or by interfering with TGF- $\beta$ binding to its receptor TGFR, ultimately inhibiting the TGF- $\beta$ /SMAD signaling pathway. In addition, CILP can inhibit the binding of IGF-1 and its receptor IGFR1. Furthermore, CILP can inhibit the function of the combination of IGF-1 and IGFR1 in NP cells and interfere with the PI3K/AKT signaling pathway, eventually leading to a decrease in ECM production, aggrecan expression, and growth and differentiation of intervertebral disc cells. CILP, cartilage intermediate layer protein; NP, nucleus pulposus; TGF- $\beta$, transforming growth factor- $\beta$; IGF-1, insulin-like growth factor-1; TGFR, transforming growth factor- $\beta$ receptors; SMAD, mothers against decapentaplegic homolog; PI3K, phosphatidylinositol-3 kinase; IGFR1, IGF-1 cell surface receptors; ECM, extracellular matrix.

IDD and the $\mathrm{C}$ allele in CILP in Japanese male collegiate athletes and judokas $(42,51)$. In another study with a Finnish population, the rs2073711 SNP was associated with IDD among women (52). It appears reasonable that the genetic susceptibility of CILP is also gender-dependent, in addition to the existing race-dependence and the substitution from the $\mathrm{T}$ to the $\mathrm{C}$ allele that changes the character of CILP, which enhances the risk of degeneration. However, given that these athletes, especially male athletes or male judokas, experience a higher mechanical loading than that of non-athletes, this phenomenon can also be explained by mechanical overloading that leads to the odds ratio discrepancy between males and females (51). Therefore, more studies are required to provide a deeper understanding of the association between CILP and IDD.

CILP is associated with other degenerative conditions, such as osteoarthritis and myocardial fibrosis. CILP was significantly increased in articular cartilage where osteoarthritis occurred, and as a key regulatory factor, it has been revealed to play an important role in the occurrence and development of osteoarthritis (53). In recent years, CILP has been regarded as an important indicator protein for myocardial fibrosis, and its expression level indicates the severity of myocardial fibrosis and plays a positive role in clinical diagnosis; decreased levels of CILP are generally considered to indicate severe myocardial fibrosis (54).

\section{Function of CILP in IDD}

With the further study on the mechanism of CILP in the development of IDD, it was revealed that the expression level of CILP in NP cells has an important effect on the ECM, an important component of the extracellular microenvironment (24). Aggrecan and collagen II are the traditional degenerative markers of IDD, which are the main components of the ECM. CILP siRNA effectively inhibited CILP expression in NP cells and significantly increased the expression of aggrecan and collagen II. In addition, treatment of NP cells with a high concentration of rhCILP resulted in significantly decreased expression of aggrecan and collagen II (24). The primary function of the intervertebral disc ECM is to ensure physical and biomechanical strength (55). The ECM plays important biological roles in chondrocyte metabolism by regulating growth factors, including TGF- $\beta(56,57)$. Studies have revealed that TGF- $\beta$ induces the synthesis of proteoglycans and cell proliferation in IVDs $(56,58)$. Furthermore, an injection of an adenoviral TGF- $\beta$ expression vector was revealed to increase proteoglycan synthesis in human IVDs (59). The TGF- $\beta$ signaling pathway is broadly involved in the growth and differentiation of cells and is responsible for the anabolism of the ECM, which is critical for the homeostasis of discs $(60,61)$. The ECM protein decorin binds to TGF- $\beta$ to form a complex that controls the accessibility of TGF- $\beta$ to receptors $(62,63)$; 
Table I. Information on the relationship between CILP and IDD.

\begin{tabular}{|c|c|c|c|}
\hline Authors & Date & Important events & (Refs.) \\
\hline Lorenzo et al & 1998 & CILP is first identified and isolated & $(18,20)$ \\
\hline Lorenzo et al & 1999 & Human CILP gene is isolated and characterized & $(44)$ \\
\hline Hirose et al & 2002 & $\begin{array}{l}\text { Increased CILP mRNA expression in chondrocytes promotes the formation of calcium } \\
\text { pyrophosphate dihydrate crystals in aged cartilage }\end{array}$ & (46) \\
\hline Johnson et al & 2003 & $\begin{array}{l}\text { CILP is revealed to promote osteoarthritis by regulating the IGF-1/PI3K/AKT } \\
\text { signaling pathway }\end{array}$ & $(68)$ \\
\hline Seki et al & 2005 & $\begin{array}{l}\text { A functional SNP in CILP, encoding cartilage intermediate layer protein, is associated with } \\
\text { susceptibility to lumbar disc disease }\end{array}$ & (19) \\
\hline Seki et al & 2005 & CILP is revealed to promote IDD by regulating the TGF- $\beta /$ SMAD signaling pathway & (19) \\
\hline Virtanen et al & 2007 & Differences of CILP gene susceptibility are revealed in different populations of IDD patients & (49) \\
\hline Seki et al & 2014 & CILP is revealed to promote lumbar disc degeneration in transgenic mice & $(25)$ \\
\hline Wang et al & 2016 & $\begin{array}{l}\text { Association between cartilage intermediate layer protein and degeneration of intervertebral } \\
\text { disc: A meta-analysis }\end{array}$ & (48) \\
\hline He et al & 2018 & $\begin{array}{l}\text { CILP is regulated by mechanical stress and affects extracellular matrix synthesis to promote } \\
\text { the progression of IDD }\end{array}$ & (24) \\
\hline
\end{tabular}

CILP, cartilage intermediate layer protein; IDD, intervertebral disc degeneration.

similarly, the binding of CILP to TGF- $\beta$ may interfere physically with the binding of TGF- $\beta$ to its receptor, or may render TGF- $\beta$ inaccessible to its receptor by sequestering TGF- $\beta$ (19). CILP has a thrombospondin type 1 repeat domain that contains the WSXW motif, a well-defined consensus sequence that binds to the active form of TGF- $\beta$; CILP coexists with TGF- $\beta$ in disc tissues and the territorial matrices of TGF- $\beta$ in IVDs (19). This interference results in the inhibition of phosphorylation of mothers against decapentaplegic homolog (SMAD)2/3, the key factors of the TGF- $\beta$ /SMAD signaling pathway (19). Furthermore, CILP is capable of suppressing the interaction of TGF- $\beta$ with its special receptor by directly binding to the growth factor, a binding that inhibits the TGF- $\beta$ signaling pathway in NP cells (25). Moreover, the phosphorylation of SMAD3, a downstream effector of TGF- $\beta$, was revealed to be suppressed in transgenic mice overexpressing CILP $(19,64)$. Alternatively, the binding of CILP may hinder the activation mechanism of TGF- $\beta$ by altering its interaction with the latency complex, and may hinder the efficacy of enzymes in releasing the active form of TGF- $\beta$ (19). In addition, the SNP (rs2073711) in the CILP gene increases the binding ability of CILP to TGF- $\beta$, consequently enhancing its suppression of the TGF- $\beta$ signaling pathway (19). In conclusion, the overexpression of CILP upsets the balance of the control of TGF- $\beta$ in chondrocyte metabolism and intervertebral disc tissue maintenance, leading to lumbar degenerative disease susceptibility caused by an inadequate response of intervertebral disc cells to injury and mechanical stress (25).

Insulin-like growth factor-1 (IGF-1) is a naturally occurring polypeptide protein hormone that plays an important role in stimulating growth during childhood and helps build and repair tissues in adults (65). In particular, IGF-1 is a key player in IVD homeostasis by upregulating both cell proliferation and the biosynthesis of ECM components in a dose-dependent manner. Once in the IVDs, IGF-1 binds to IGF-1 cell surface receptors (IGFR1), initiating the phosphatidylinositol-3 kinase/AKT signaling pathway, stimulating cell growth and proliferation, and inhibiting programmed cell death, which leads to an increase in IVD cell population and the production of new ECM $(66,67)$. CILP is capable of suppressing ligand-induced IGFR1 autophosphorylation and counteracting IGF-1-mediated chondrocyte proliferation and proteoglycan synthesis (68-70), thus interfering with the anabolism and catabolism of ECM, which leads to the acceleration of IDD. Other studies have reported that IGF-1 can reduce inorganic pyrophosphate ( $\mathrm{PPi}$ ), which can be generated via the alkaline nucleotide phosphodiesterase I activity of the isozymes of the NPP family (71) and is able to promote the progression of CPPD crystal deposition in aging cartilage tissues (46); in addition, CILP can affect chondrocyte IGF-1 responsiveness via $\mathrm{N}$-terminal domain-mediated inhibition (68), leading to a PPi increase that can stimulate cartilage pathological calcification as CPPD crystal deposition (72). Cartilage pathological calcification can cause the degeneration of the CEP, which decreases the availability of nutrients and the exchange of metabolites, resulting in irreversible and progressive IDD (73-75).

These studies have revealed that CILP can interfere with the binding of $>1$ growth factor to their designated receptor, and can suppress downstream signal transduction, consequently affecting the general homeostasis of cells (Fig. 4).

\section{Regulation of CILP}

As CILP has been revealed to function as a contributor to IDD, it is imperative to provide insight into the regulatory mechanism underlying CILP expression. First, CILP expression is increased as age and degeneration progress $(23,26)$; therefore, aging and degeneration are among the causes that promote CILP expression. Notably, as a structural component in the matrix secreted by chondrocytes, CILP was expressed without 
the effect of SOX9 (45), which is the core transcription factor in chondrogenesis (76-78). Instead, TGF- $\beta$, another key regulator of chondrocyte differentiation and proliferation (60), is able to promote the secretion of CILP by NP cells through the SMAD and MAPK signaling pathways (45). With regard to the CILP-mediated suppression of the TGF- $\beta$ signaling pathway via the binding of CILP to TGF- $\beta$ (19), there appears to be a negative feedback loop between CILP and TGF- $\beta$. Similarly, bone morphogenetic protein 2 (BMP-2) also significantly increases CILP expression by increasing CILP promoter activity through the SMAD signaling pathway, an effect that increases with age (23). However, in contrast to TGF- $\beta$ and BMP-2, IGF-1 downregulates CILP expression by binding to the N-terminal polypeptide domain of CILP (68). These results indicated that the regulatory effect on CILP by growth factors varies by type, and that the dysregulated secretion of growth factors may contribute to the aberrant expression of CILP. In addition, since IDD is characterized by an enhanced level of inflammatory chemokines, including IL and TNF $(17,79)$, which have a significant influence on the secretion of NP cells, it is possible that a high level of inflammatory chemokines may regulate CILP expression. However, it was revealed CILP expression does not undergo a significant change even in a conditioned medium with a high level of IL-1, markedly increasing the expression of MMPs and ADAMTs (80). It remains unknown whether CILP is also unaffected by other inflammatory factors, and this requires further study for clarification. CILP expression is also influenced by mechanical factors; in human NP cells, CILP expression is regulated by mechanical stress, which affects the synthesis of ECM (24). In conclusion, these results suggested that, as a structural protein resident in the ECM, CILP expression is upregulated by aging and degeneration but is unaffected by IL-1; in addition, various growth factors exert different, even contrary, regulations on CILP, which in turn affect the secretion of those growth factors.

\section{Conclusions and future directions}

As an NP matrix protein, CILP is specifically expressed in degenerative IVD tissues, which can accelerate the progression of IDD by altering the balance of intervertebral disc matrix metabolism.

CILP is an ECM glycoprotein that is highly expressed in degenerative disc tissues and accelerates the process of disc degeneration by altering the balance of the intervertebral disc matrix metabolism (18). Since the first discovery of CILP, the regulation, expression and function of CILP have been elucidated in numerous studies (Table I). Disc degeneration is a chronic metabolic disorder of the extracellular microenvironment. Several ECM proteins, such as CILP and connective tissue growth factor (81), are involved in this process. The end result of these cytokine pathways is an imbalance of catabolism and anabolism within the disc, leading to disc degeneration, herniation, and radicular pain. A recent study has revealed that the expression and function of CILP are regulated by specific tissue and cell types (82). In intervertebral disc-related studies, CILP regulates the role of cytokines such as TGF- $\beta$ and IGF-1 in IVDs $(25,68,82)$. The TGF- $\beta /$ CILP mutual regulation is important for ECM production and the two-way regulation of TGF- $\beta$ and CILP $(25,82)$. The TGF- $\beta /$ SMAD axis is inhibited by CILP eventually leading to the decrease of ECM production and aggrecan expression, as well as inhibiting programmed cell death and growth and differentiation of IVD cells (25). The activation of BMP-2 also increases CILP expression through the SMAD signaling pathway (25). In contrast to TGF- $\beta$ and BMP-2, the activation of IGF-1 downregulates CILP expression, thereby inhibiting the progression of disc degeneration. IGF-1 binds to IGFR1, activating the PI3K/AKT signaling pathway, promoting cell growth and proliferation, and inhibiting programmed cell death, which leads to an increase in IVD cell population and the production of new ECM (68). In a recent study, it was revealed that mechanical changes in the disc are another important regulatory factor of CILP (24). Increased CILP expression induced by mechanical changes in the disc NP cells can promote the process of disc tissue degeneration. In the intervertebral disc, mechanical alteration is a physiological niche condition, and in order to maintain its physiological level, it may be necessary to reduce unnecessary mechanical alteration. During disc degeneration, the blood oxygen status of NP is thought to be altered due to vascular infiltration. Therefore, a reasonable reduction of TGF- $\beta$ and increase of IGF-1 expression can reduce the expression level of CILP in the disc. Further research on the role of CILP in the degenerative disc and surrounding tissues is required to determine the ultimate role of CILP in this process.

In vivo and in vitro studies have clearly revealed that CILP affects the anabolic effects of nucleus pulposus (CMCS) on stroma production, and that it may be able to use the properties of this protein as part of a regenerative mix to treat degenerative discs. However, there have been no clinical trials of CILP-related therapy. To further investigate CILP-related therapy, understanding the relationship between CILP and tissue inflammation will be important for the successful treatment of disc disease.

\section{Acknowledgements}

The authors would like to thank the Department of Orthopedics of Xinqiao Hospital (Chongqing, China) for their support.

\section{Funding}

This research was funded by the National Natural Science Foundation of China (grant nos. 81902255, 81874028 and 81672215).

\section{Availability of data and materials}

Data sharing is not applicable to this article, as no datasets were generated or analyzed during the current study.

\section{Authors' contributions}

LL and $\mathrm{JH}$ were responsible for conceiving the study, and are the co-first authors. CLiu, MY, JF, ML, YoZ, JY and XA were responsible for literature collection and summary. YaZ, BH, $\mathrm{CLi}, \mathrm{YuZ}$ and $\mathrm{CF}$ were responsible for reviewing and editing the manuscript. YZ and CF were responsible for supervising the study. All authors have read and approved the published version of the manuscript. 


\section{Ethics approval and consent for publication}

All subjects provided their informed consent before participating in the study. The study was conducted in accordance with the Declaration of Helsinki. The study was approved by the Ethics Committee of Xinqiao Hospital (Chongqing, China) on October 1, 2019 at the implementation of the study.

\section{Patient consent for publication}

Not applicable.

\section{Competing interests}

The authors declare that they have no competing interests.

\section{References}

1. Andersson GB: Epidemiological features of chronic low-back pain. Lancet 354: 581-585, 1999.

2. Martin BI, Deyo RA, Mirza SK, Turner JA, Comstock BA, Hollingworth W and Sullivan SD: Expenditures and health status among adults with back and neck problems. Jama 299: 656-664, 2008.

3. Yang W, Yu XH, Wang C, He WS, Zhang SJ, Yan YG, Zhang J, Xiang YX and Wang WJ: Interleukin-1beta in intervertebral disk degeneration. Clin Chim Acta 450: 262-272, 2015.

4. Luoma K, Riihimäki H, Luukkonen R, Raininko R, Viikari-Juntura E and Lamminen A: Low back pain in relation to lumbar disc degeneration. Spine (Phila Pa 1976) 25: 487-492, 2000.

5. Takatalo J, Karppinen J, Niinimäki J, Taimela S, Näyhä S, Mutanen P, Sequeiros RB, Kyllönen E and Tervonen O: Does lumbar disc degeneration on magnetic resonance imaging associate with low back symptom severity in young finnish adults? Spine (Phila Pa 1976) 36: 2180-2189, 2011.

6. Antoniou J, Goudsouzian NM, Heathfield TF, Winterbottom N, Steffen T, Poole AR, Aebi M and Alini M: The human lumbar endplate. Evidence of changes in biosynthesis and denaturation of the extracellular matrix with growth, maturation, aging, and degeneration. Spine 21: 1153-1161, 1996.

7. Guterl CC, See EY, Blanquer SB, Pandit A, Ferguson SJ, Benneker LM, Grijpma DW, Sakai D, Eglin D, Alini M, et al: Challenges and strategies in the repair of ruptured annulus fibrosus. Eur Cell Mater 25: 1-21, 2013.

8. Yang X and X Li: Nucleus pulposus tissue engineering: A brief review. Eur Spine J 18: 1564-1572, 2009.

9. Edgar MA: The nerve supply of the lumbar intervertebral disc. J Bone Joint Surg Br 89: 1135-1139, 2007.

10. Pattappa G, Li Z, Peroglio M, Wismer N, Alini M and Grad S: Diversity of intervertebral disc cells: Phenotype and function. J Anat 221: 480-496, 2012.

11. Adams MA and Roughley PJ: What is intervertebral disc degeneration, and what causes it? Spine 31: 2151-2161, 2006.

12. Antoniou J, Steffen T, Nelson F, Winterbottom N, Hollander AP, Poole RA, Aebi M and Alini M: The human lumbar intervertebral disc: Evidence for changes in the biosynthesis and denaturation of the extracellular matrix with growth, maturation, ageing, and degeneration. J Clin Invest 98: 996-1003, 1996.

13. Wuertz K, Vo N, Kletsas D and Boos N: Inflammatory and catabolic signalling in intervertebral discs: The roles of NF-kB and MAP kinases. Eur Cell Mater 23: 103-119, 2012.

14. Kepler CK, Markova DZ, Dibra F, Yadla S, Vaccaro AR, Risbud MV, Albert TJ and Anderson DG: Expression and relationship of proinflammatory chemokine RANTES/CCL5 and cytokine IL-1 $\beta$ in painful human intervertebral discs. Spine 38: 873-880, 2013.

15. Feng C, Liu H, Yang M, Zhang Y, Huang B and Zhou Y: Disc cell senescence in intervertebral disc degeneration: Causes and molecular pathways. Cell Cycle 15: 1674-1684, 2016.

16. Sivan SS, Hayes AJ, Wachtel E, Caterson B, Merkher Y, Maroudas A, Brown S and Roberts S: Biochemical composition and turnover of the extracellular matrix of the normal and degenerate intervertebral disc. Eur Spine J 23 (Suppl 3): S344-S353, 2014.
17. Molinos M, Almeida CR, Caldeira J, Cunha C, Gonçalves RM and Barbosa MA: Inflammation in intervertebral disc degeneration and regeneration. J R Soc Interface 12: 20141191, 2015.

18. Lorenzo P, Bayliss MT and Heinegard D: A novel cartilage protein (CILP) present in the mid-zone of human articular cartilage increases with age. J Biol Chem 273: 23463-23468, 1998.

19. Seki S, Kawaguchi Y, Chiba K, Mikami Y, Kizawa H, Oya T, Mio F, Mori M, Miyamoto Y, Masuda I, et al: A functional SNP in CILP, encoding cartilage intermediate layer protein, is associated with susceptibility to lumbar disc disease. Nat Genet 37: 607-612, 2005.

20. Lorenzo P, Neame P, Sommarin Y and Heinegård D: Cloning and deduced amino acid sequence of a novel cartilage protein (CILP) identifies a proform including a nucleotide pyrophosphohydrolase. J Biol Chem 273: 23469-23475, 1998.

21. Cardenal A, Masuda I, Haas AL, Ono W and McCarty DJ: Identification of a nucleotide pyrophosphohydrolase from articular tissues in human serum. Arthritis Rheum 39: 252-256, 1996.

22. Masuda I, Cardenal A, Ono W, Hamada J, Haas AL and McCarty DJ: Nucleotide pyrophosphohydrolase in human synovial fluid. J Rheumatol 24: 1588-1594, 1997.

23. Wang Z, Kim JH, Higashino K, Kim SS, Wang S, Seki S, Hutton WC and Yoon ST: Cartilage intermediate layer protein (CILP) regulation in intervertebral discs. The effect of age, degeneration, and bone morphogenetic protein-2. Spine (Phila Pa 1976) 37: E203-E208, 2012.

24. He J, Feng C, Sun J, Lu K, Chu T, Zhou Y and Pan Y: Cartilage intermediate layer protein is regulated by mechanical stress and affects extracellular matrix synthesis. Mol Med Rep 17: 6130-6137, 2018.

25. Seki S, Tsumaki N, Motomura H, Nogami M, Kawaguchi Y, Hori T, Suzuki K, Yahara Y, Higashimoto M, Oya T, et al: Cartilage intermediate layer protein promotes lumbar disc degeneration. Biochem Biophys Res Commun 446: 876-881, 2014.

26. Yee A, Lam MP, Tam V, Chan WC, Chu IK, Cheah KS, Cheung KM and Chan D: Fibrotic-like changes in degenerate human intervertebral discs revealed by quantitative proteomic analysis. Osteoarthritis Cartilage 24: 503-513, 2016.

27. Roberts S, Evans H, Trivedi J and Menage J: Histology and pathology of the human intervertebral disc. J Bone Joint Surg Am 88 (Suppl 2): S10-S14, 2006.

28. Kanayama M, Togawa D, Takahashi C, Terai T and Hashimoto T: Cross-sectional magnetic resonance imaging study of lumbar disc degeneration in 200 healthy individuals. J Neurosurg Spine 11: 501-507, 2009.

29. Adams MA, Freeman BJ, Morrison HP, Nelson IW and Dolan P: Mechanical initiation of intervertebral disc degeneration. Spine (Phila Pa 1976) 25: 1625-1636, 2000.

30. Battie MC, Videman T, Kaprio J, Gibbons LE, Gill K, Manninen H, Saarela J and Peltonen L: The Twin Spine Study: Contributions to a changing view of disc degeneration. Spine J 9: 47-59, 2009.

31. Wang D, Nasto LA, Roughley P, Leme AS, Houghton AM, Usas A, Sowa G, Lee J, Niedernhofer L, Shapiro S, et al: Spine degeneration in a murine model of chronic human tobacco smokers. Osteoarthritis Cartilage 20: 896-905, 2012.

32. Le Maitre CL, Freemont AJ and Hoyland JA: The role of interleukin-1 in the pathogenesis of human intervertebral disc degeneration. Arthritis Res Ther 7: R732-R745, 2005.

33. Le Maitre CL, Hoyland JA and Freemont AJ: Catabolic cytokine expression in degenerate and herniated human intervertebral discs: IL-1beta and TNFalpha expression profile. Arthritis Res Ther 9: R77, 2007.

34. Karli P, Martlé V, Bossens K, Summerfield A, Doherr MG, Turner P, Vandevelde M, Forterre F and Henke D: Dominance of chemokine ligand 2 and matrix metalloproteinase-2 and -9 and suppression of pro-inflammatory cytokines in the epidural compartment after intervertebral disc extrusion in a canine model. Spine J 14: 2976-2984, 2014.

35. Yamamoto J, Maeno K, Takada T, Kakutani K, Yurube T, Zhang Z, Hirata H, Kurakawa T, Sakai D, Mochida J, et al: Fas ligand plays an important role for the production of pro-inflammatory cytokines in intervertebral disc nucleus pulposus cells. J Orthop Res 31: 608-615, 2013.

36. Kepler CK, Markova DZ, Hilibrand AS, Vaccaro AR, Risbud MV, Albert TJ and Anderson DG: Substance P stimulates production of inflammatory cytokines in human disc cells. Spine (Phila Pa 1976) 38: E1291-E1299, 2013. 
37. Singh K, Masuda K, Thonar EJ, An HS and Cs-Szabo G: Age-related changes in the extracellular matrix of nucleus pulposus and anulus fibrosus of human intervertebral disc. Spine (Phila Pa 1976) 34: 10-16, 2009.

38. Vo NV, Hartman RA, Yurube T, Jacobs LJ, Sowa GA and Kang JD: Expression and regulation of metalloproteinases and their inhibitors in intervertebral disc aging and degeneration. Spine J 13: 331-341, 2013

39. Freemont AJ, Watkins A, Le Maitre C, Baird P, Jeziorska M, Knight MT, Ross ER, O'Brien JP and Hoyland JA: Nerve growth factor expression and innervation of the painful intervertebral disc. J Pathol 197: 286-292, 2002.

40. Melrose J, Roberts S, Smith S, Menage J and Ghosh P: Increased nerve and blood vessel ingrowth associated with proteoglycan depletion in an ovine anular lesion model of experimental disc degeneration. Spine (Phila Pa 1976) 27: 1278-1285, 2002.

41. Harshitha SM, Sibin MK, Chetan GK and Dhananjaya I Bhat: Association of CILP, COL9A2 and MMP3 gene polymorphisms with lumbar disc degeneration in an Indian population. J Mol Neurosci 66: 378-382, 2018.

42. Min SK, Nakazato K, Yamamoto Y, Gushiken K, Fujimoto H, Fujishiro H, Kobayakawa $\mathrm{Y}$ and Hiranuma K: Cartilage intermediate layer protein gene is associated with lumbar disc degeneration in male, but not female, collegiate athletes. Am J Sports Med 38: 2552-2557, 2010

43. Nakamura I, Okawa A, Ikegawa S, Takaoka K and Nakamura Y: Genomic organization, mapping, and polymorphisms of the gene encoding human cartilage intermediate layer protein (CILP). J Hum Genet 44: 203-205, 1999.

44. Lorenzo P, Aman P, Sommarin Y and Heinegård D: The human CILP gene: Exon/intron organization and chromosomal mapping Matrix Biol 18: 445-454, 1999.

45. Mori M, Nakajima M, Mikami Y, Seki S, Takigawa M, Kubo T and Ikegawa S: Transcriptional regulation of the cartilage intermediate layer protein (CILP) gene. Biochem Biophys Res Commun 341: 121-127, 2006.

46. Hirose J, Ryan LM and Masuda I: Up-regulated expression of cartilage intermediate-layer protein and ANK in articular hyaline cartilage from patients with calcium pyrophosphate dihydrate crystal deposition disease. Arthritis Rheum 46: 3218-3129, 2002

47. Bernardo BC, Belluoccio D, Rowley L, Little CB, Hansen U and Bateman JF: Cartilage intermediate layer protein 2 (CILP-2) is expressed in articular and meniscal cartilage and down-regulated in experimental osteoarthritis. J Biol Chem 286: 37758-33767, 2011.

48. Wang W, Hao J, Zheng S, Xiao X, Wen Y, He A, Guo X and Zhang F: Association between cartilage intermediate layer protein and degeneration of intervertebral disc: A meta-analysis. Spine (Phila Pa 1976) 41: E1244-E1248, 2016.

49. Virtanen IM, Song YQ, Cheung KM, Ala-Kokko L, Karppinen J, Ho DW, Luk KD, Yip SP, Leong JC, Cheah KS, et al: Phenotypic and population differences in the association between CILP and lumbar disc disease. J Med Genet 44: 285-288, 2007.

50. Rajasekaran S, Kanna RM, Senthil N, Raveendran M, Cheung KM, Chan D, Subramaniam S and Shetty AP: Phenotype variations affect genetic association studies of degenerative disc disease: Conclusions of analysis of genetic association of 58 single nucleotide polymorphisms with highly specific phenotypes for disc degeneration in 332 subjects. Spine J 13: 1309-1320,2013

51. Min SK, Nakazato K, Ishigami $\mathrm{H}$ and Hiranuma K: Cartilage intermediate layer protein and asporin polymorphisms are independent risk factors of lumbar disc degeneration in male collegiate athletes. Cartilage 5: 37-42, 2014.

52. Kelempisioti A, Eskola PJ, Okuloff A, Karjalainen U, Takatalo J, Daavittila I, Niinimäki J, Sequeiros RB, Tervonen O, Solovieva $S$, et al: Genetic susceptibility of intervertebral disc degeneration among young Finnish adults. BMC Med Genet 12: 153,2011

53. Taipale M, Solovieva S, Leino-Arjas $\mathrm{P}$ and Männikkö $\mathrm{M}$ : Functional polymorphisms in asporin and CILP together with joint loading predispose to hand osteoarthritis. BMC Genetics 18: 108, 2017.

54. Park S, Ranjbarvaziri S, Zhao P and Ardehali R: Cardiac fibrosis is associated with decreased circulating levels of full-length CILP in heart failure. JACC Basic Transl Sci 5: 432-443, 2020.

55. Hayes AJ, Benjamin M and Ralphs JR: Extracellular matrix in development of the intervertebral disc. Matrix Biol 20: 107-121, 2001.
56. Pattison ST, Melrose J, Ghosh P and Taylor TK: Regulation of gelatinase-A (MMP-2) production by ovine intervertebral disc nucleus pulposus cells grown in alginate bead culture by Transforming Growth Factor-beta(1)and insulin like growth factor-I. Cell Biol Int 25: 679-689, 2001

57. Chen J, Yan W and Setton LA: Static compression induces zonal-specific changes in gene expression for extracellular matrix and cytoskeletal proteins in intervertebral disc cells in vitro. Matrix Biol 22: 573-583, 2004.

58. Wang H, Kroeber M, Hanke M, Ries R, Schmid C, Poller W and Richter W: Release of active and depot GDF-5 after adenovirus-mediated overexpression stimulates rabbit and human intervertebral disc cells. J Mol Med (Berl) 82: 126-134, 2004

59. Nishida K, Kang JD, Gilbertson LG, Moon SH, Suh JK, Vogt MT, Robbins PD and Evans CH: Modulation of the biologic activity of the rabbit intervertebral disc by gene therapy: An in vivo study of adenovirus-mediated transfer of the human transforming growth factor beta 1 encoding gene. Spine (Phila Pa 1976) 24: 2419-2425, 1999

60. Grimaud E, Heymann D and Redini F: Recent advances in TGF-beta effects on chondrocyte metabolism. Potential therapeutic roles of TGF-beta in cartilage disorders. Cytokine Growth Factor Rev 13: 241-257, 2002.

61. de Caestecker M: The transforming growth factor-beta superfamily of receptors. Cytokine Growth Factor Rev 15: 1-11, 2004.

62. Border WA, Noble NA, Yamamoto T, Harper JR, Yamaguchi YU, Pierschbacher MD and Ruoslahti E: Natural inhibitor of transforming growth factor-beta protects against scarring in experimental kidney disease. Nature 360: 361-364, 1992.

63. Isaka Y, Brees DK, Ikegaya K, Kaneda Y, Imai E, Noble NA and Border WA: Gene therapy by skeletal muscle expression of decorin prevents fibrotic disease in rat kidney. Nat Med 2: 418-423, 1996

64. Derynck R and Zhang YE: Smad-dependent and Smad-independent pathways in TGF-beta family signalling. Nature 425: 577-584, 2003

65. Laron Z: Insulin-like growth factor 1 (IGF-1): A growth hormone. Mol Pathol 54: 311-316, 2001

66. Foulstone E, Prince S, Zaccheo O, Burns JL, Harper J, Jacobs C, Church D and Hassan AB: Insulin-like growth factor ligands, receptors, and binding proteins in cancer. J Pathol 205: 145-153, 2005.

67. Liu ZQ, Zhao S and Fu WQ: Insulin-like growth factor 1 antagonizes lumbar disc degeneration through enhanced autophagy. Am J Transl Res 8: 4346-4353, 2016.

68. Johnson K, Farley D, Hu SI and Terkeltaub R: One of two chondrocyte-expressed isoforms of cartilage intermediate-layer protein functions as an insulin-like growth factor 1 antagonist. Arthritis Rheum 48: 1302-1314, 2003.

69. Olmez U, Ryan LM, Kurup IV and Rosenthal AK: Insulin-like growth factor-1 suppresses pyrophosphate elaboration by transforming growth factor beta1-stimulated chondrocytes and cartilage. Osteoarthritis Cartilage 2: 149-154, 1994.

70. Abu Shehab M, Iosef C, Wildgruber R, Sardana G and Gupta MB: Phosphorylation of IGFBP-1 at discrete sites elicits variable effects on IGF-I receptor autophosphorylation. Endocrinology 154: 1130-1143, 2013.

71. Russell RG, Bisaz S, Fleisch H, Currey HL, Rubinstein HM, Dietz AA, Boussina I, Micheli A and Fallet G: Inorganic pyrophosphate in plasma, urine, and synovial fluid of patients with pyrophosphate arthropathy (chondrocalcinosis or pseudogout). Lancet 2: 899-902, 1970.

72. Johnson K and Terkeltaub R: Inorganic pyrophosphate (PPI) in pathologic calcification of articular cartilage. Front Biosci 10 988-997, 2005.

73. Liu MH, Sun C, Yao Y, Fan X, Liu H, Cui YH, Bian XW, Huang B and Zhou Y: Matrix stiffness promotes cartilage endplate chondrocyte calcification in disc degeneration via miR-20a targeting ANKH expression. Sci Rep 6: 25401, 2016.

74. Roberts S, Urban JP, Evans H and Eisenstein SM: Transport properties of the human cartilage endplate in relation to its composition and calcification. Spine (Phila Pa 1976) 21: 415-420, 1996.

75. Moore RJ: The vertebral endplate: Disc degeneration, disc regeneration. Eur Spine J 15 Suppl 3(Suppl 3): S333-S337, 2006.

76. Lefebvre V, Li P and De Crombrugghe B: A new long form of Sox 5 (L-Sox5), Sox6 and Sox 9 are coexpressed in chondrogenesis and cooperatively activate the type II collagen gene. Embo J 17: 5718-5733, 1998 
77. de Crombrugghe B, Lefebvre V, Behringer RR, Bi W, Murakami S and Huang W: Transcriptional mechanisms of chondrocyte differentiation. Matrix Biol 19: 389-394, 2000.

78. Ikeda T, Kamekura S, Mabuchi A, Kou I, Seki S, Takato T, Nakamura K, Kawaguchi H, Ikegawa S and Chung UI: The combination of SOX5, SOX6, and SOX9 (the SOX trio) provides signals sufficient for induction of permanent cartilage. Arthritis Rheum 50: 3561-3573, 2004.

79. Wang C, Yu X, Yan Y, Yang W, Zhang S, Xiang Y, Zhang J and Wang W: Tumor necrosis factor- $\alpha$ : A key contributor to intervertebral disc degeneration. Acta Biochim Biophys Sin (Shanghai) 49: 1-13, 2017.

80. Clutterbuck AL, Smith JR, Allaway D, Harris P, Liddell S and Mobasheri A: High throughput proteomic analysis of the secretome in an explant model of articular cartilage inflammation. J Proteomics 74: 704-715, 2011.
81. Tran CM, Shapiro IM and Risbud MV: Molecular regulation of CCN2 in the intervertebral disc: Lessons learned from other connective tissues. Matrix Biol 32: 298-306, 2013.

82. Zhang CL, Zhao Q, Liang H, Qiao X, Wang JY, Wu D, Wu LL and Li L: Cartilage intermediate layer protein-1 alleviates pressure overload-induced cardiac fibrosis via interfering TGF- $\beta 1$ signaling. J Mol Cell Cardiol 116: 135-144, 2018.

This work is licensed under a Creative Commons Attribution-NonCommercial-NoDerivatives 4.0 International (CC BY-NC-ND 4.0) License. 